JURNAL ILMIAH KOMPUTERISASI AKUNTANSI, Vol. 14, No. 1, Juli 2021, pp. 1 - 13

p-ISSN : 1979-116X (print)

e-ISSN : 2614-8870 (online)

http://journal.stekom.ac.id/index.php/kompak

\title{
Program Aplikasi Pengelolaan Kas Menggunakan Php Pada Klinik Dyna
} Banjarmasin

\author{
Muhammad Syahid Pebriadi ${ }^{1}$, Ahsanul Haq ${ }^{2}$, Fuji Melania ${ }^{3}$ \\ ${ }^{1}$ Komputerisasi Akuntansi Politeknik Negeri Banjarmasin, e-mail: m.syahid@poliban.ac.id \\ ${ }^{2}$ Komputerisasi Akuntansi Politeknik Negeri Banjarmasin, e-mail: ahsanul@akuntansipoliban.ac.id \\ ${ }^{3}$ Komputerisasi Akuntansi Politeknik Negeri Banjarmasin, e-mail: fujimelania10@gmail.com
}

\begin{tabular}{|c|c|}
\hline ARTICLE INFO & ABSTRACT \\
\hline $\begin{array}{l}\text { Article history: } \\
\text { Received } 30 \text { Mei } 2021 \\
\text { Received in revised form } 2 \text { Juni } 2021 \\
\text { Accepted } 10 \text { Juni } 2021 \\
\text { Available online } 12 \text { Juni } 2021\end{array}$ & $\begin{array}{l}\text { Clinic is a health service institution that is used to } \\
\text { provide medical services needed by the community. } \\
\text { The clinic aims to help improve the quality of health } \\
\text { in the community and the clinic can be managed by } \\
\text { the government or the private sector. In order to } \\
\text { create good and fast service to the community, it can } \\
\text { be supported by computerized accounting records. } \\
\text { The purpose of this study is to determine the } \\
\text { appropriate cash management accounting } \\
\text { information system at DYNA Clinic in Banjarmasin, } \\
\text { as well as to produce a Web-Based Cash } \\
\text { Management Application Program This study found } \\
\text { that all cash records at the DYNA clinic were still } \\
\text { manual. The author suggests using a web-based cash } \\
\text { management application program to help DYNA } \\
\text { Clinic record patient data, record cash management } \\
\text { transactions and make it easier to find information } \\
\text { on cash receipts and disbursements. }\end{array}$ \\
\hline
\end{tabular}

Keywords: Accounting system information, Webbased Cash management application program.

\section{Pendahuluan}

Pada saat ini sistem informasi akuntansi sangat berperan penting dalam membantu kinerja dalam sebuah perusahaan atau instansi dalam mengerjakan laporan keuangannya, sehingga data yang dihasilkan tertata dengan baik dan dapat mempercepat dalam proses pengolahan data transaksi [1]. Pada Instansi yang bergerak dalam bidang pelayanan kesehatan seperti klinik sistem informasi adalah sistem yang dapat menunjang kegiatan transaksi dalam instansi tersebut. Klinik merupakan institusi pelayanan kesehatan yang digunakan untuk memberikan jasa pelayanan medis yang diperlukan oleh masyarakat. Klinik bertujuan untuk membantu meningkatkan kualitas kesehatan pada masyarakat dan klinik dapat dikelola pemerintah maupun pihak swasta. Agar terciptanya pelayanan yang baik dan cepat pada masyarakat, dapat ditunjang dengan melakukan pencatatan akuntansi secara terkomputerisasi. Pencatatan akuntansi yang berhubungan dengan klinik salah satunya adalah pencatatan penerimaan kas dan pengeluaran kas.

Klinik ini masih menerapkan pencatatan manual dan belum menerapkan sistem pencatatan keuangan yang terkomputerisasi pada pengelolaan keuangannya. Kondisi tersebut mengakibatkan hasil laporan keuangan yang cenderung kurang akurat dikarenakan tidak dapat mengontrol transaksi keuangan setiap harinya. Bahkan terdapat masalah pada proses administrasi pasien yang datang untuk konsultasi, dokter atau petugas administrasi harus mendata satu per satu

Received Mei 23, 2021; Revised Juni 29, 2021; Accepted Juli 12, 2021 
pasien dengan menggunakan kartu periksa pasien namun ada pula pasien yang sudah terdaftar tetapi tidak membawa kartu periksanya hal ini menyebabkan pihak administrasi kesulitan dalam proses pelayanan setiap harinya dalam pendataan, mendiagnosa pasien dan memberikan tindakan medis kepada pasien. Pada pencatatan pengelolaan kas pada Klinik DYNA Banjarmasin saat ini masih menggunakan proses pencatatan manual dengan pencatatan transaksi ditulis ke dalam buku biasa dan tidak adanya pengarsipan pada transaksi yang terjadi hal tersebut dapat memicu adanya kesalahan pencatatan seperti tidak tercatatnya penerimaan kas dan pengeluaran kas serta dapat mengakibatkan keterlambatan pencatatan dalam pembuatan laporan.

Beberapa peneliti memanfaatkan sistem informasi yang berbasis akuntansi untuk membantu mempercepat proses pelayanan. Purwantini, $d k k$ [2] mengembangkan sistem informasi akuntansi penerimaan dan pengeluaran kas untuk membantu sekolah SMK mengelola dana kas berupa dana SPP dan dan Bantuan Operasional Sekolah. Agus, dkk [3] membuat aplikasi web yang digunakan untuk mencatat transaksi dan laporan keuangan. Abdullah, dkk [1] mengembangkan aplikasi web untuk pengelolaan kas masuk dan kas keluar sehingga dapat menyajikan laporan kas masuk dan kas keluar dengan cepat dan akurat.

Berdasarkan permasalahan yang telah diuraikan pada latar belakang penulis tertarik untuk membuat sistem yang masih manual agar dapat diperbaiki menjadi sistem aplikasi berbasis web dengan menggunakan PHP agar dapat menginput data secara baik, cepat dan terprogram. Dengan adanya aplikasi berbasis web dalam penginputan data dan pengolahan datanya diharapkan dapat membantu dalam setiap kegiatan penyusunan laporan penerimaan kas dan pengeluaran kas. Keuntungan yang dapat dirasakan dalam penggunaan aplikasi berbasis web, antara lain aplikasi tersebut dapat dikembangkan dengan mudah, dapat menyesuaikan kebutuhan hal ini mempermudah pengguna dalam mengetahui informasi yang diinginkan karena bisa diakses dimana saja dan kapan saja (dengan syarat memiliki koneksi internet dan browser) dan interface lebih fleksibel.

\section{Landasan Teori}

\subsection{Sistem Informasi dan Kas}

Sistem informasi dapat dijelaskan sebagai sebuah rangkaian prosedur formal dimana data dikelompokkan, diproses menjadi informasi, dan didistribusikan kepada pemakai [4].

Sedangkan sistem yang berfungsi untuk mengumpulan, mencatat, menyimpan, dan memproses data sehingga menghasilkan informasi bagi para pengambil keputusan dikenal dengan istilah Sistem Informasi Akuntansi (SIA). SIA dapat berupa sistem manual maupun sistem kompleks yang menggunakan teknologi terbaru [5].

Kas adalah segala sesuatu (baik yang berbentuk uang atau bukan) yang dapat digunakan sebagai alat pembayaran atau alat pelunasan kewajiban. Termasuk kas adalah rekening giro di bank (cash in bank), dan uang kas yang ada di perusahaan (cash on hand). Kas dalam perusahaan merupakan harta yang paling lancar, sehingga dalam neraca ditempatkan paling atas dalam kelompok paling atas [6].

\subsection{Sistem Akuntansi Penerimaan Kas}

Sistem akuntansi penerimaan kas merupakan satu jaringan prosedur yang dibuat menurut pola yang terpadu untuk melaksanakan kegiatan penerimaan kas dari penjualan rutin dan tidak rutin berdasarkan ketentuan-ketentuan dari perusahaan yang bersangkutan [7].

\subsection{Sistem Akuntansi Pengeluaran Kas}

Sistem akuntansi pengeluaran kas merupakan catatan yang dibuat untuk melaksanakan kegiatan pengeluaran baik dengan cek maupun dengan uang tunai yang digunakan untuk kegiatan umum perusahaan [7].

\subsection{Klinik}

JURNAL ILMIAH KOMPUTERISASI AKUNTANSI Vol. 14, No. 1, Juli 2020: 1-13 
Klinik adalah fasilitas untuk memberikan jasa pelayanan medis yang diperlukan oleh masyarakat. Klinik memberikan pelayanan kesehatan perorangan dengan memberikan pelayanan medis dasar dan/atau spesialistik, terdapat lebih dari satu jenis tenaga kerja kesehatan dan dipimpin oleh seorang tenaga medis (dokter, dokter spesialis atau dokter gigi).

Berdasarkan jenis pelayanannya, klinik dibagi menjadi klinik pratama dan klinik utama. Kedua macam klinik ini dapat diselenggarakan oleh pemerintah, pemerintah daerah atau masyarakat. Klinik pratama adalah klinik yang menyelenggarakan pelayanan medik dasar. Klinik utama adalah klinik yang menyelenggarakan pelayanan medik spesialistik atau pelayanan medik dasar dan spesialistik. Sifat pelayanan kesehatan yang diselenggarakan bisa berupa rawat jalan, one day care, rawat inap dan/atau home care.

\subsection{Sistem Pengendalian Internal}

Sistem pengendalian intern meliputi struktur organisasi, metode dan ukuran-ukuran yang dikoordinasikan untuk menjaga kekayaan organisasi, mengecek ketelitian dan keandalan data akuntansi, mendorong efisiensi dan mendorong terjadinya kebijakan manajemen. Definisi sistem pengendalian intern tersebut menekankan tujuan yang hendak dicapai, dan bukan pada unsurunsur yang membentuk sistem tersebut, dengan demikian pengertian pengendalian intern tersebut diatas berlaku baik dalam perusahaan yang mengolah informasinya secara manual, dengan mesin pembukuan, maupun dengan komputer [7].

\section{Metode Penelitian}

\subsection{Sumber Data}

\subsubsection{Data Primer}

Data primer merupakan data yang didapat dari sumber pertama baik dari individu atau perseorangan. Pada penelitian ini, data primer yang diperoleh berupa struktur organisasi, prosedur yang digunakan dan fungsi-fungsi terkait.

\subsubsection{Data Sekunder}

Data sekunder merupakan data primer yang telah diolah lebih kanjut dan disajikan, baik oleh pengumpulu data primer atau pihak lain. Data sekunder yang diperoleh antara lain data tanda pembayaran, data pasien, data kas masuk dan kas keluar.

\subsection{Pengumpulan Data}

\subsubsection{Wawancara}

Wawancara secara langung dilakukan kepada pemilik klinik. Wawancara dilakukan untuk mendapatkan informasi mengenai sejarah, kegiatan operasi dan transaksi-transaksi yang dilakuakn dalam menjalankan usaha setiap harinya pada klinik tersebut yang berkaitan dengan permasalahan.

\subsubsection{Dokumentasi}

Dokumentasi dilakukan dengan mengumpulkan data-data sekunder dari pihak klinik. Dokumentasi yang diperlukan yaitu catatan-catatan akuntansi (seperti nota dan struk). Serta dokumen-dokumen yang digunakan dalam proses penerimaan dan pengeluaran kas.

\subsection{Pengembangan Sistem}

\subsubsection{Analisa Sistem}

Tahap analisa sistem dilakukan untuk mengetahui bagaimana proses bisnis yang dilakukan secara manual dapat diadaptasi menjadi proses bisnis yang terkomputerisasi. Pada tahapan ini kegiatan yang dilakukan yaitu mengumpulkan berbagai informasi dan data yang dapat

Program Aplikasi Pengelolaan Kas Menggunakan Php Pada Klinik Dyna Banjarmasin (Muhammad Syahid Pebriadi) 
dianalisis seperti struktur organisasi, fungsi - fungsi yang terkait, catatan akuntansi yang digunakan, dokumen - dokumen yang digunakan, Jaringan prosedur yang membentuk sistem, sistem pengendalian intern yang melekat pada Sistem Iinformasi Akuntansi penerimaan dan pengeluaran kas tersebut, bagan alir sistemnya, dan lain-lain yang dianggap perlu untuk membantu penulis dalam menganalisis sistem penerimaan dan pengeluaran kas pada klinik DYNA Banjarmasin.

\subsubsection{Perancangan Sistem}

a. Desain Database

Membuat desain tabel- tabel yang diperlukan sesuai dengan kebutuhan, seperti tabel user, meliputi tabel data dokter, table data pasien, tabel daftar tindakan dan tabel transaksi lainnya yang berhubungan dengan penerimaan dan pengeluaran kas pada Klinik DYNA Banjarmasin. Membuat relasi antara tabel-tabel yang telah dibuat dihubungkan dengan cara direlasikan sesuai dengan bentuk normal ketiga (3NF) agar tidak terjadi perulangan

b. Desain Masukkan

Membuat desain masukan yang terdiri dari desain data dokter, data pasien, data petugas, desain transaksi penerimaan dan pengeluaran kas.

c. Desain Keluaran

Membuat desain yang akan menjadi output meliputi laporan harian, laporan pasien, laporan penerimaan kas dan laporan pengeluaran kas.

\subsubsection{Implementasi}

Implementasi merupakan tahap pengembangan yang meliputi proses pembuatan, pengujian, dan pengoperasian program. Dalam tahapan ini penulis membuat program berdasarkan desain yang telah dibuat dengan menggunakan PHP. Program yang telah dibuat selanjutnya akan dilakukan pengujian dan pengoperasian berdasarkan data yang telah didapat pada tahap sebelumnya.

\subsubsection{Uji Coba Sistem}

Tahapan ini dilakukan untuk mengetahui fungsionalitas dari aplikasi yang sudah di implementasikan. Uji coba sistem menggunakan Black Box Testing, yang melakukan pengujian terhadap setiap fungsi atau fitur yang ada pada sistem.Implementasi merupakan tahap pengembangan yang meliputi proses pembuatan, pengujian, dan pengoperasian program. Dalam tahapan ini penulis membuat program berdasarkan desain yang telah dibuat dengan menggunakan PHP. Program yang telah dibuat selanjutnya akan dilakukan pengujian dan pengoperasian berdasarkan data yang telah didapat oleh Penulis.

\section{Hasil dan Pembahasan}

\subsection{Sistem Informasi Penerimaan Kas}

Keperluan informasi yang disarankan kepada pihak manajemen yaitu Laporan Penerimaan kas per tanggal (harian) dan laporan penerimaan kas keseluruhan. Selanjutnya, fungsi yang terkait dalam sistem penerimaan kas yaitu fungsi administrasi, fungsi kasir dan fungsi akuntansi. Fungsi ini memiliki fungsinya masing-masing dimana fungsi administrasi harus dipisahkan dengan fungsi kasir. 


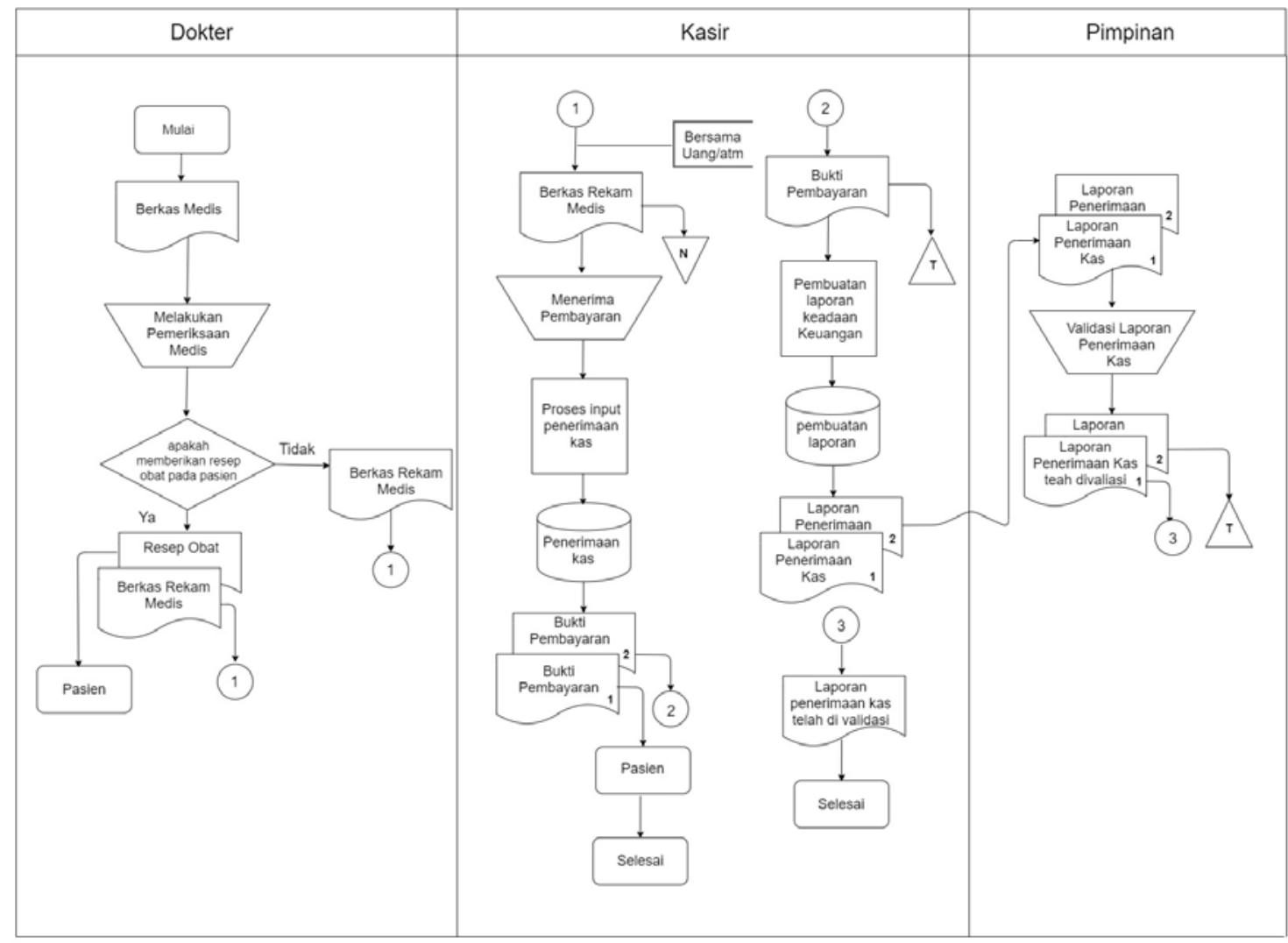

Gambar 1. Alir Dokumen Penerimaan Kas yang disarankan

Berdasarkan bagan alir dokumen penerimaan kas yang berjalan pada Klinik DYNA Banjarmasin dapat dijelaskan sebagai berikut:

a) Bagian Dokter

1) Melakukan pemeriksaan medis kepada pasien

2) Mencatat rekam medis pasien

3) Memberikan resep obat kepada pasien

b) Bagian Kasir

1) Menerima pembayaran dari pasien

2) Memberikan bukti pembayaran kepada pasien

3) Mencatat penerimaan kas pada laporan harian

c) Pimpinan

1) Mencek laporan penerimaan kas

\subsection{Sistem Informasi Pengeluaran Kas}

Keperluan informasi bagi pihak manajemen untuk sistem pengeluaran kas yaitu Laporan pembelian per nota dan laporan buku kas. Sedangkan fungsi terkait yang disarankan yaitu fungsi akuntansi yang bertanggung jawab untuk melakukan pengeluaran kas dan pencatatan pengeluaran kas serta membuat laporan. 


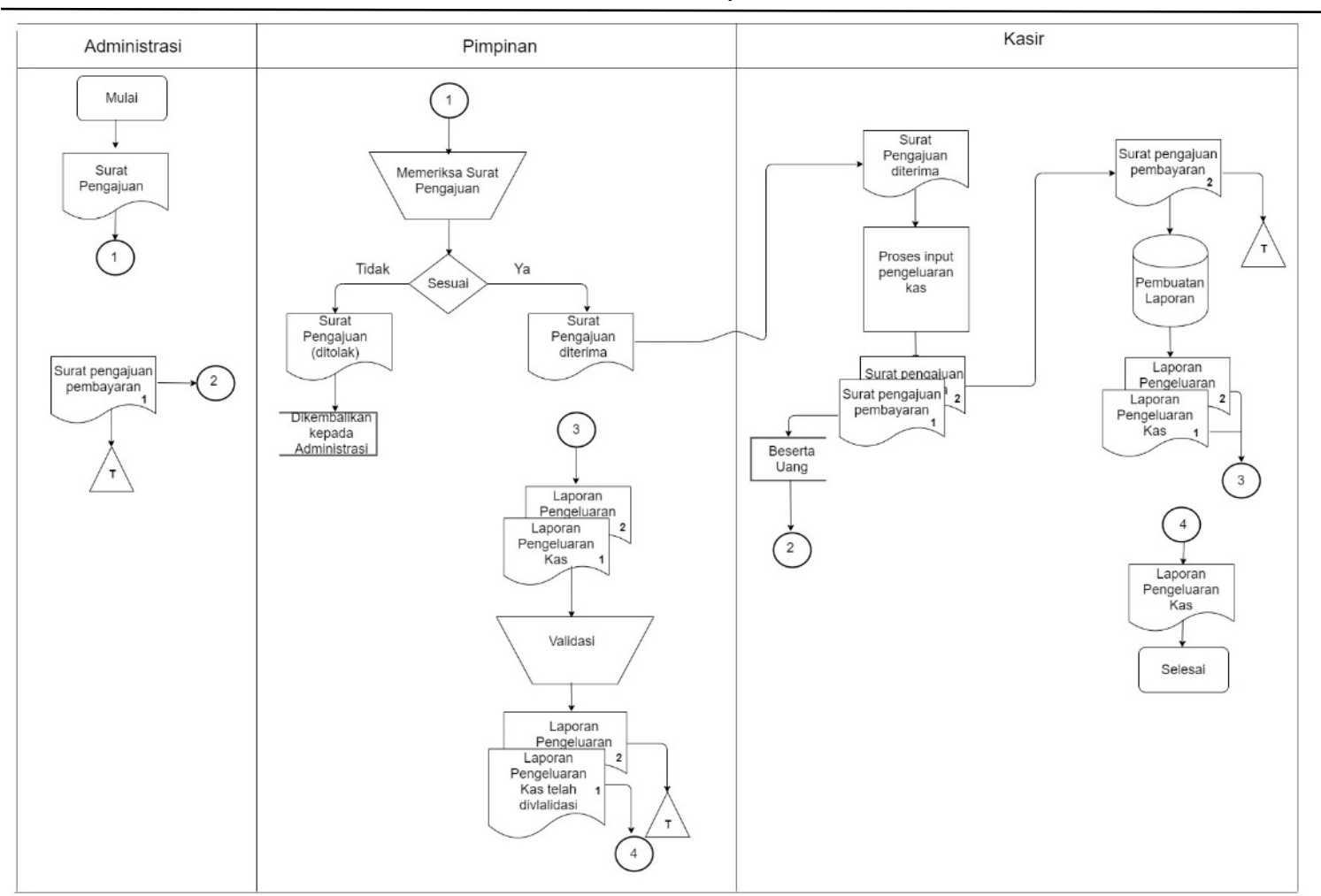

Gambar 2. Alir Dokumen Pengeluaran Kas yang Disarankan

Berdasarkan bagan alir dokumen pengeluaran kas dari penjualan tunai pada Klinik DYNA Banjramasin yang disarankan dapat dijelaskan sebagai berikut:

a) Administrasi

1) Mengajukan surat pengajuan pada saat ada keperluan untuk proses pengeluaran kas

b) Pemilik / Pimpinan

1) Memeriksa kesesuaian surat pengajuan

c) Keuangan

1) Menerima surat pengajuan yang sudah diperiksa pimpinan

2) Membuatkan bukti perintah pengeluaran uang

3) Melakukan pencatatan pada laporan pengeluaran kas

\subsection{Basis Data}

JURNAL ILMIAH KOMPUTERISASI AKUNTANSI Vol. 14, No. 1, Juli $2020: 1$ - 13 


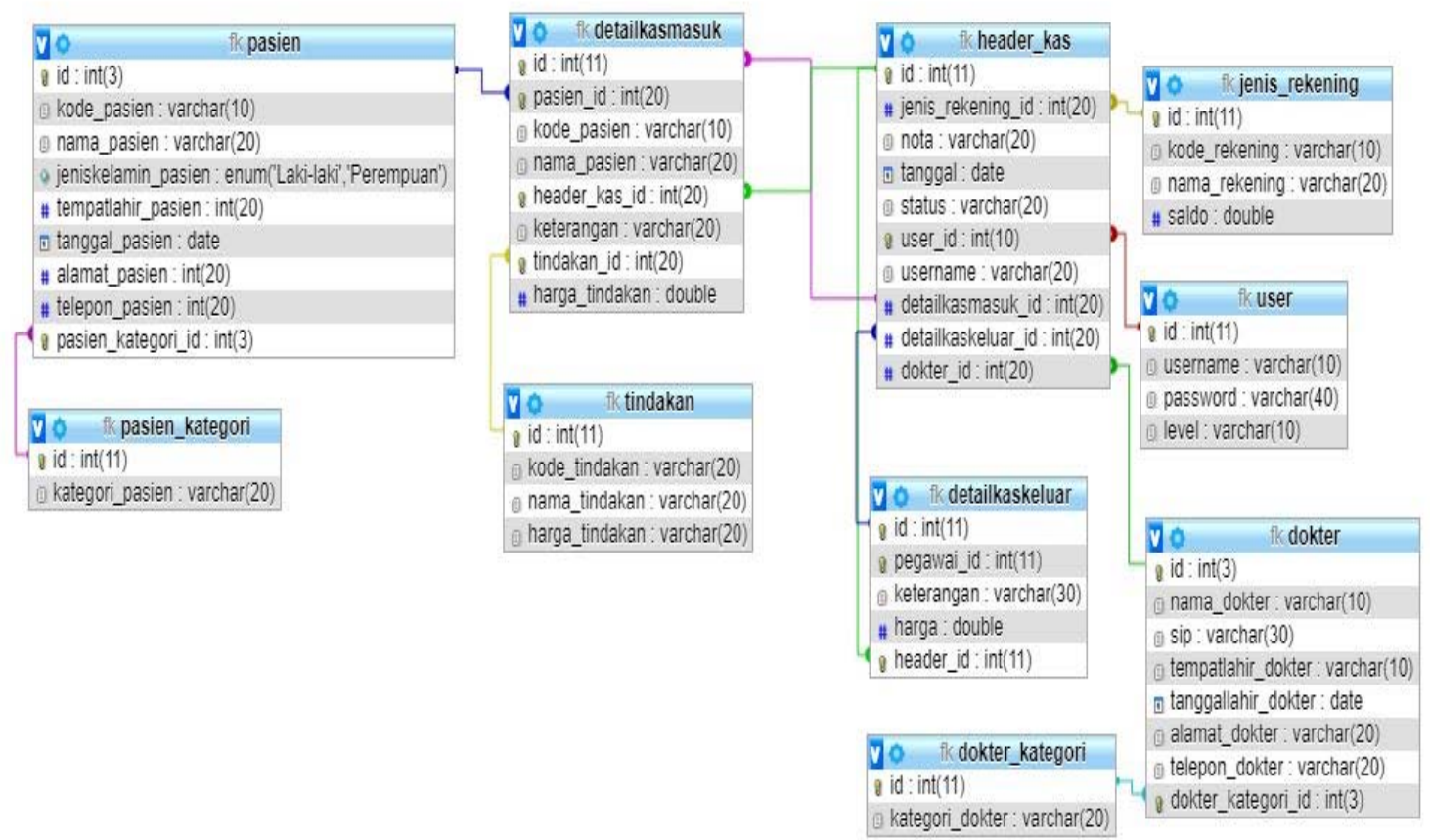

Gambar 3. Basis Data Klinik Dyna Banjarmasin

Keterangan:

a) Tabel User

Tabel user adalah tabel yang digunakan untuk menyimpan data user dan menambahkan data user yang baru. Tabel ini memiliki jenis relasi one to many ke tabel header_kas dengan field kunci id. Hal ini berarti bahwa satu jenis kode user bisa mempunyai banyak transaksi pada tabel header_kas.

b) Tabel Pasien

Tabel pasien adalah tabel yang digunakan untuk menyimpan dan menambahkan data pasien. Tabel ini memiliki relasi one to many dengan tabel detailkasmasuk dengan field kunci id. Hal ini berarti bahwa satu jenis kode pasien bisa mempunyai banyak detail kode pada tabel detailkasmasuk.

c) Tabel Dokter

Tabel dokter adalah tabel yang digunakan untuk menyimpan dan menambahkan data dokter. Tabel ini memiliki relasi one to many dengan tabel detailkasmasuk dengan field kunci id. Hal ini berarti bahwa satu jenis kode pasien bisa mempunyai banyak detail kode pada tabel detailkasmasuk.

d) Tabel Kategori Pasien

Tabel pasien_kategori adalah tabel yang digunakan untuk menyimpan data jenis pasien dan menambahkan data jenis pasien yang baru. Tabel ini memiliki jenis relasi one to many ke tabel pasien dengan field kunci id. Hal ini berarti bahwa satu jenis kode jenis pasien bisa mempunyai banyak detail kode pada tabel pasien.

e) Tabel Kategori Dokter

Tabel dokter_kategori adalah tabel yang digunakan untuk menyimpan data jenis pasien dan menambahkan data jenis dokter yang baru. Tabel ini memiliki jenis relasi one to many ke tabel dokter dengan field kunci id. Hal ini berarti bahwa satu jenis kode jenis dokter bisa mempunyai banyak detail kode pada tabel dokter. 
f) Tabel Tindakan

Tabel tindakan adalah tabel yang digunakan untuk menyimpan dan menambahkan data tindakan. Tabel ini memiliki relasi one to many dengan tabel detailkasmasuk dengan field kunci id. Hal ini berarti bahwa satu jenis kode tindakan bisa mempunyai banyak detail kode pada tabel detailkasmasuk.

g) Tabel Jenis Rekening

Tabel rekening_kas adalah tabel yang digunakan untuk menyimpan data rekening kas yang dipakai. Tabel ini memiliki jenis relasi one to many ke tabel header_kas dengan field kunci id. Hal ini berarti bahwa satu jenis rekening kas bisa mempunyai banyak transaksaki pada tabel header kas.

h) Tabel Detail Kas Masuk

Tabel detailkasmasuk adalah tabel yang digunakan untuk menyimpan data detail transaksi penerimaan kas dan menambahkan data detail yang baru. Tabel ini memiliki jenis relasi many to one ke tabel header_kas dengan field kunci id. Hal ini berarti bahwa beberapa kode transaksi detail mempunyai satu transaksi pada tabel header_kas.

i) Tabel Detail Kas Keluar

Tabel detailkaskeluar adalah tabel yang digunakan untuk menyimpan data detail transaksi pengeluaran kas dan menambahkan data detail yang baru. Tabel ini memiliki jenis relasi many to one ke tabel header_kas dengan field kunci id. Hal ini berarti bahwa beberapa kode transaksi detail mempunyai satu transaksi pada tabel header_kas.

j) Tabel Header_Kas

Tabel header_kas adalah tabel yang digunakan untuk menyimpan data transaksi header dan menambahkan data header yang baru. Tabel ini memiliki jenis relasi one to many ke tabel detailkasmasuk dan detailkaskeluar dengan field kunci id. Hal ini berarti bahwa satu jenis kode header bisa mempunyai banyak transaksi pada tabel detailkasmasuk dan detailkaskeluar.

\subsection{Implementasi}

\subsubsection{Form Login}

Form login merupakan halaman pertama yang ditampilkan saat program aplikasi dijalankan untuk bisa masuk ke dalam program aplikasi maka user perlu memasukkan username dan password terlebih dahulu.

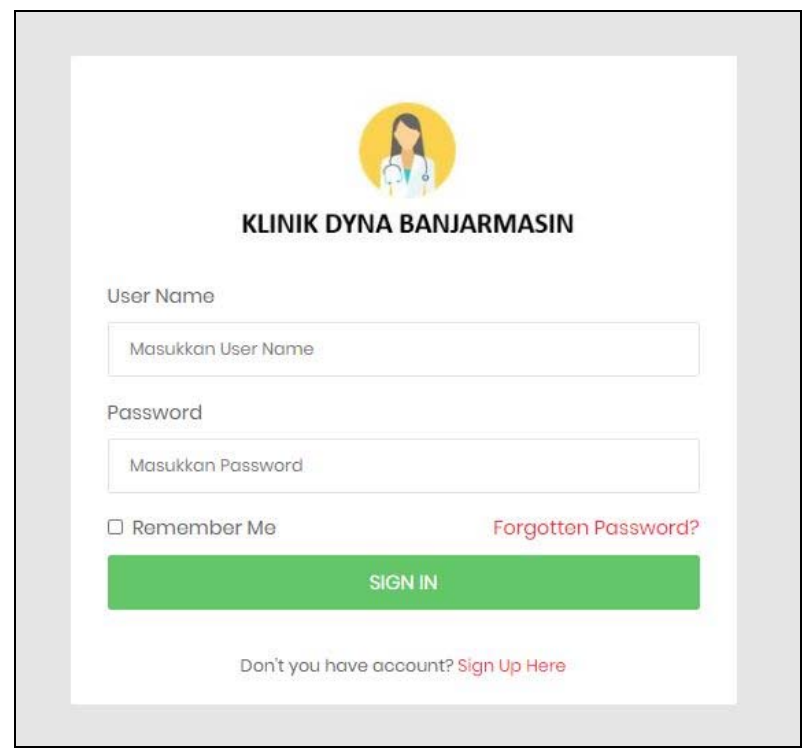

Gambar 4. Form Login

JURNAL ILMIAH KOMPUTERISASI AKUNTANSI Vol. 14, No. 1, Juli $2020: 1$ - 13 


\subsubsection{Form Menu Utama}

Form menu utama merupakan form yang muncul pertama kali setelah proses login dilakukan. Lalu, di bagian samping terdepat berbagai macam menu untuk berbagai macam transaksi yang ingin dilakukan. Berikut tampilan form menu utama.

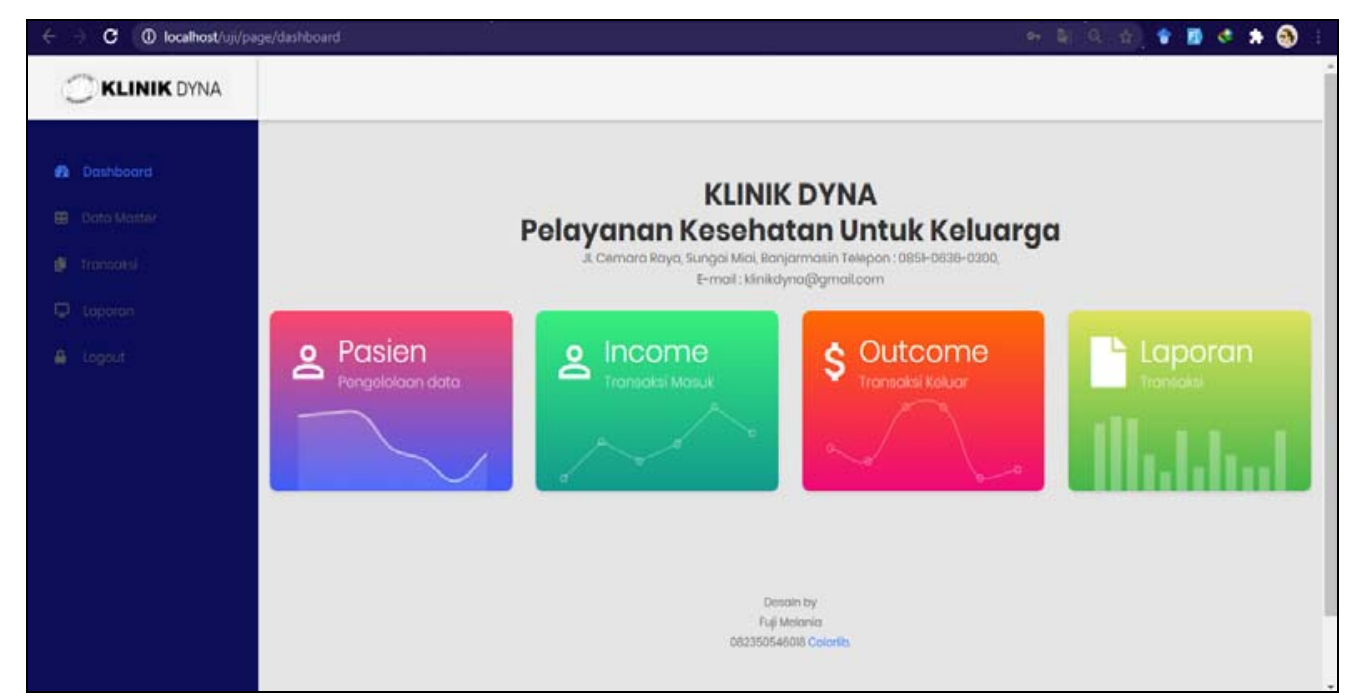

Gambar 5. Form Menu Utama

\subsubsection{Form Master Data Pasien}

Form Master Pasien digunakan untuk menyimpan informasi data pasien seperti alamat, no telepon, kategori, tempat dan tanggal lahir.

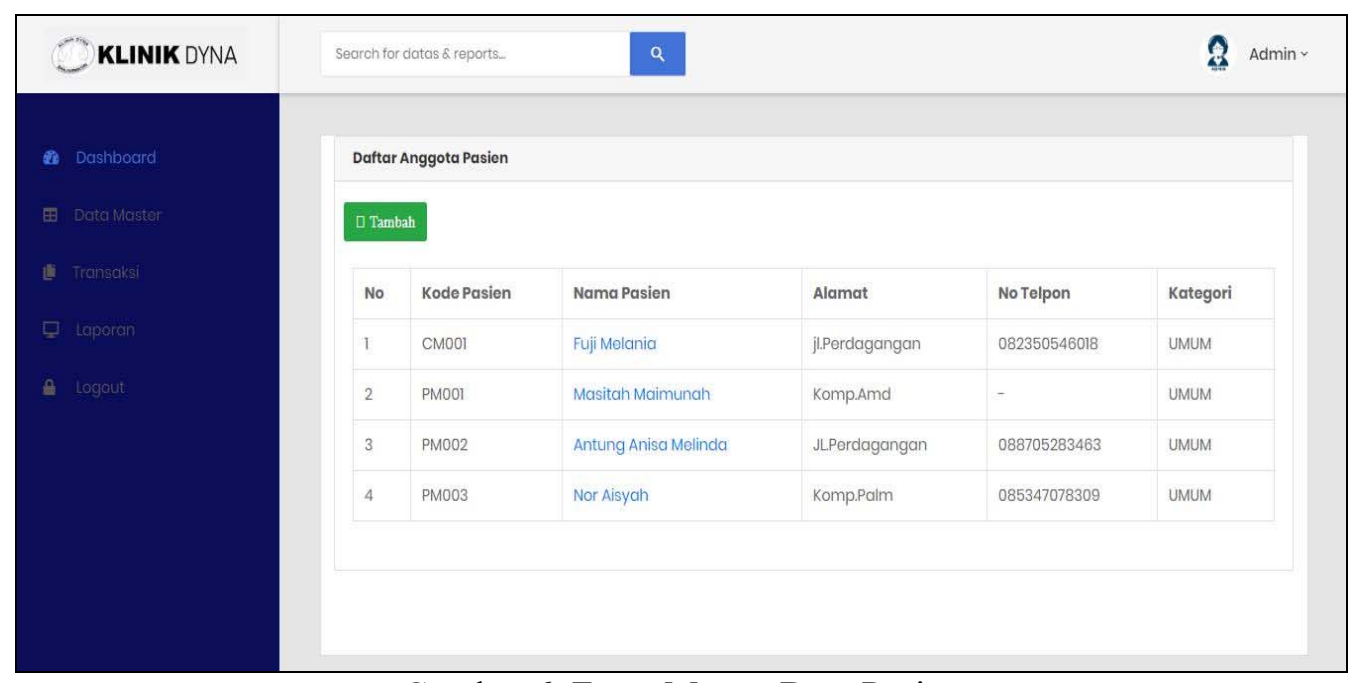

Gambar 6. Form Master Data Pasien

\subsubsection{Form Master Data Dokter}

Form Master Dokter digunakan untuk menyimpan informasi data Dokter seperti alamat, no telepon, kategori dokter, SIP, tempat dan tanggal lahir. 


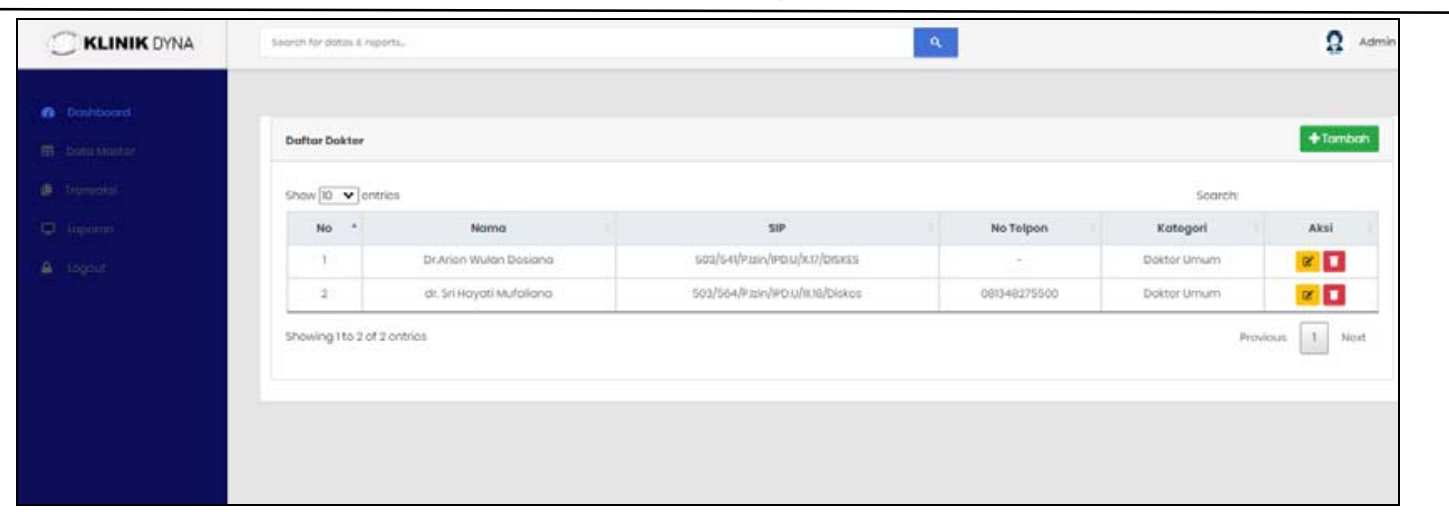

Gambar 7. Form Master Data Dokter

\subsubsection{Form Master Data Tindakan}

Form Master Tindakan digunakan untuk menyimpan informasi data tindakan seperti nama tindakan, harga Tindakan.

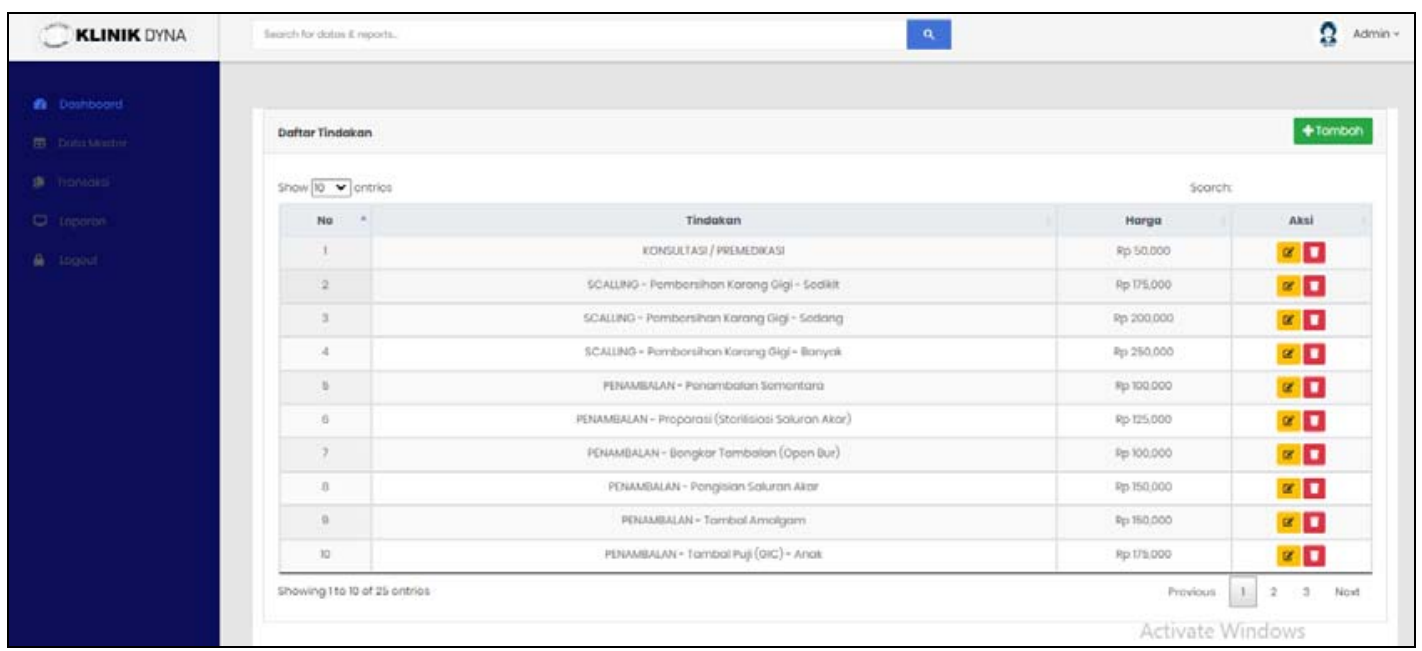

Gambar 8. Form Master Data Tindakan

\subsubsection{Form Transaksi Penerimaan Kas}

Form transaksi Penerimaan kas merupakan form yang digunakan pada saat terjadinya transaksi penerimaan kas dan pasien melakukan pembayaran kepada kasir, pada saat kasir menginputkan data sesuai jasa layanan yang diberikan dan otomatis mencetak nota.

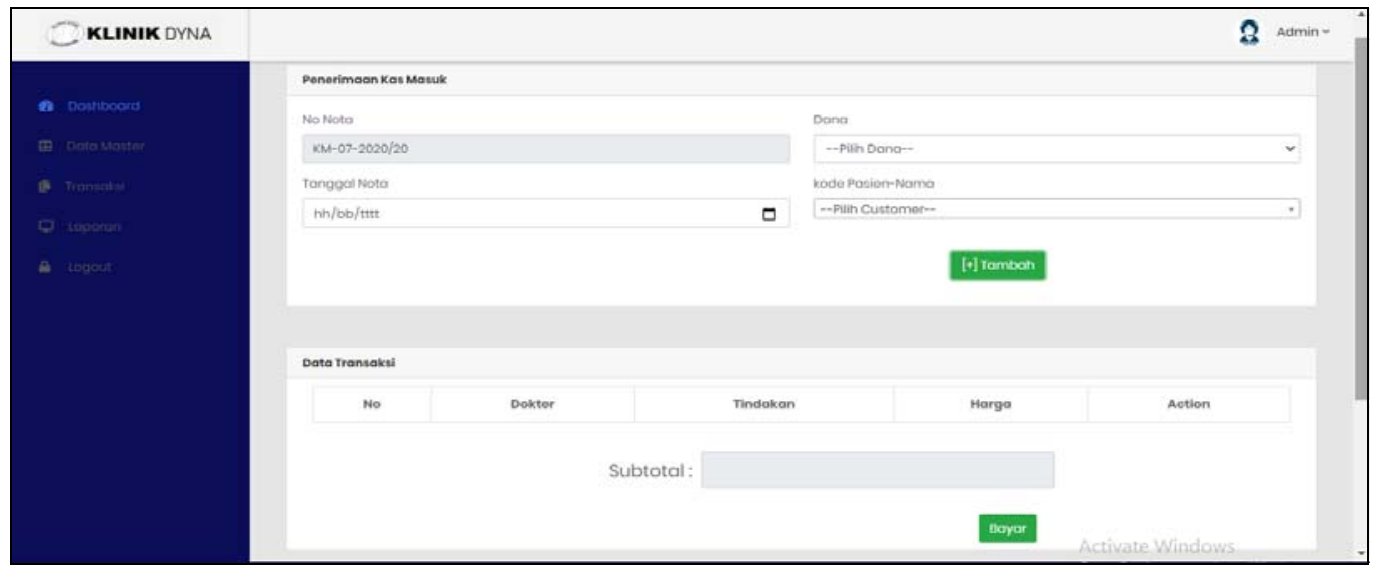

JURNAL ILMIAH KOMPUTERISASI AKUNTANSI Vol. 14, No. 1, Juli 2020: 1-13 
11

Gambar 9. Form Transaksi Penerimaan Kas

\subsubsection{Form Transaksi Pengeluaran Kas}

Form transaksi Pengeluaran kas merupakan form yang digunakan pada saat terjadinya transaksi pengeluaran kas maupun melakukan biaya operasional.

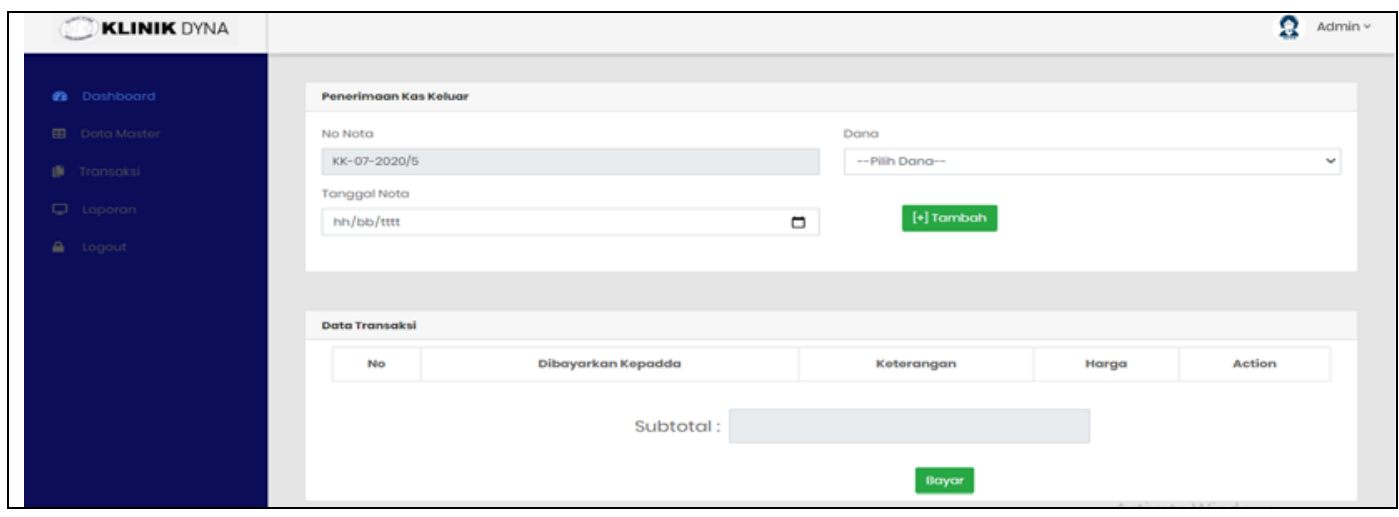

Gambar 10. Form Transaksi Pengeluaran Kas

\subsubsection{Laporan Penerimaan Kas}

Laporan Penerimaan Kas digunakan untuk informasi kas masuk yang sifatnya tidak dapat diubah atau di hapus oleh pengguna,

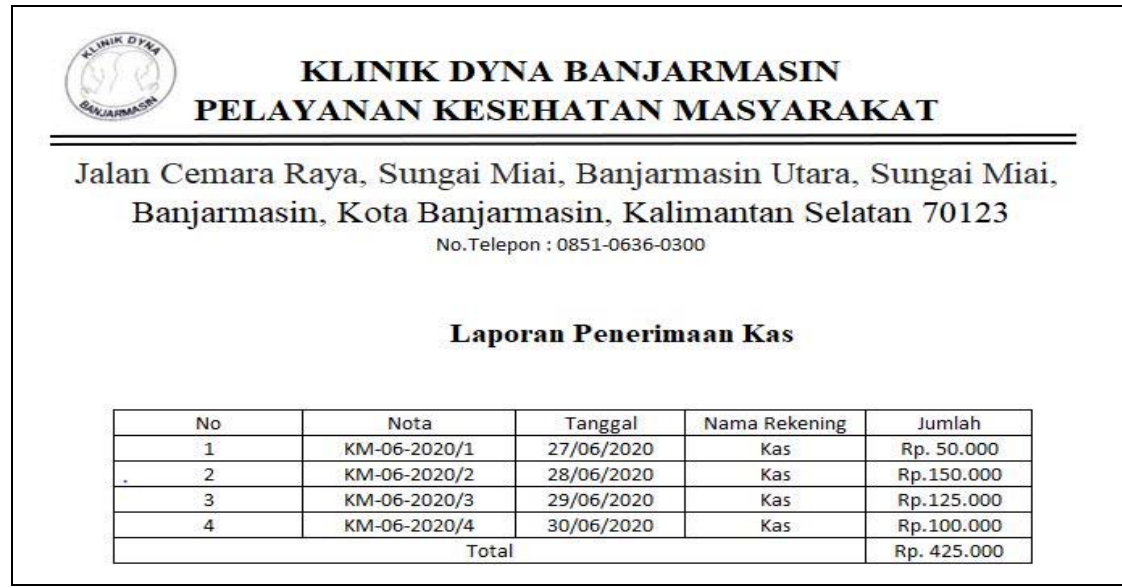

Gambar 11. Laporan Penerimaan Kas

\subsubsection{Laporan Pengeluaran Kas}

Laporan Pengeluaran Kas digunakan untuk informasi kas keluar yang sifatnya tidak dapat diubah atau di hapus oleh pengguna. 


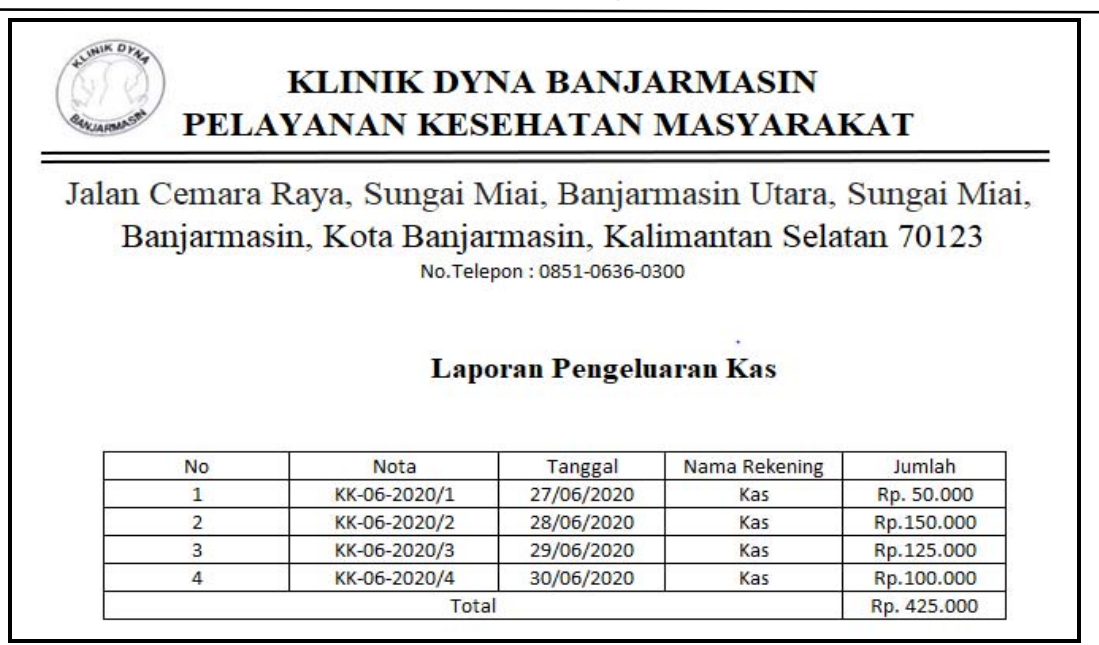

Gambar 12. Laporan Pengeluaran Kas

\subsection{Uji Coba Sistem}

Hasil pengujian sistem menggunakan black box testing dapat dilihat pada tabel 1 .

Tabel 1. Hasil Uji Coba Fungsionalitas

\begin{tabular}{|c|c|c|c|c|}
\hline \multirow[b]{2}{*}{ No } & \multirow{2}{*}{$\begin{array}{l}\text { Kategori Yang di } \\
\text { Ujikan }\end{array}$} & \multirow[b]{2}{*}{ Pertanyaan Hasil } & \multicolumn{2}{|c|}{ Hasil } \\
\hline & & & $\mathrm{Y}$ & $\mathrm{T}$ \\
\hline 1 & Login & Apakah fungsi Login berfungsi dengan benar? & $\sqrt{ }$ & \\
\hline 2 & Menu Dashboard & Apakah fungsi Dashboard dapat difungsikan? & $\sqrt{ }$ & \\
\hline 3 & Menu Pasien & Apakah fungsi Pasien dapat difungsikan? & $\sqrt{ }$ & \\
\hline 4 & Menu Dokter & Apakah fungsi Dokter dapat difungsikan? & $\sqrt{ }$ & \\
\hline 5 & Menu Tindakan & Apakah fungsi Tindakan dapat difungsikan? & $\sqrt{ }$ & \\
\hline 6 & Menu Kas & Apakah fungsi Kas dapat difungsikan? & $\sqrt{ }$ & \\
\hline 7 & Menu User & Apakah fungsi User dapat difungsikan? & $\sqrt{ }$ & \\
\hline 8 & $\begin{array}{l}\text { Transaksi Penerimaan } \\
\text { Kas }\end{array}$ & $\begin{array}{l}\text { Apakah fungsi Transaksi Penerimaan kas berfungsi dengan } \\
\text { benar? }\end{array}$ & $\sqrt{ }$ & \\
\hline 9 & $\begin{array}{l}\text { Transaksi } \\
\text { Pengeluaran Kas }\end{array}$ & $\begin{array}{l}\text { Apakah fungsi Transaksi Pengeluaran kas berfungsi dengan } \\
\text { benar? }\end{array}$ & $\sqrt{ }$ & \\
\hline 10 & $\begin{array}{l}\text { Daftar Penerimaan } \\
\text { Kas }\end{array}$ & $\begin{array}{l}\text { Apakah fungsi Daftar Penerimaan kas berfungsi dengan benar } \\
\text { ? }\end{array}$ & $\sqrt{ }$ & \\
\hline 11 & $\begin{array}{l}\text { Daftar Pengeluaran } \\
\text { Kas }\end{array}$ & $\begin{array}{l}\text { Apakah fungsi Daftar Penerimaan kas berfungsi dengan benar } \\
\text { ? }\end{array}$ & $\sqrt{ }$ & \\
\hline 12 & $\begin{array}{l}\text { Laporan Penerimaan } \\
\text { Kas }\end{array}$ & $\begin{array}{l}\text { Apakah fungsi Laporan Penerimaan kas berfungsi dengan } \\
\text { benar? }\end{array}$ & $\sqrt{ }$ & \\
\hline 13 & $\begin{array}{l}\text { Laporan Pengeluaran } \\
\text { Kas }\end{array}$ & $\begin{array}{l}\text { Apakah fungsi Laporan Pengeluaran kas berfungsi dengan } \\
\text { benar? }\end{array}$ & $\sqrt{ }$ & \\
\hline 14 & Laporan Rekapitulasi & Apakah fungsi Rekapitulasi berfungsi dengan benar? & $\sqrt{ }$ & \\
\hline 15 & Laporan Buku Besar & Apakah fungsi Laporan Buku Besar berfungsi dengan benar? & $\sqrt{ }$ & \\
\hline
\end{tabular}

JURNAL ILMIAH KOMPUTERISASI AKUNTANSI Vol. 14, No. 1, Juli $2020: 1$ - 13 


\section{Kesimpulan}

Sistem informasi pengelolaan kas pada Klinik DYNA Banjarmasin sudah berjalan dengan baik dengan adanya sistem pengendalian internal dalam pemisahan fungsi pencatatan penerimaan yang melibatkan admin dan kasir sedangkan pengeluaran kas hanya melibatkan fungsi kasir. Program Aplikasi Pengelolaan kas Menggunakan PHP pada Klinik DYNA Banjarmasin dibuat sesuai siklus akuntansi, yaitu dari dokumen transaksi yang diinput kedalam pemasukkan dan pengeluaran kas, kemudian dibuatkan output berupa laporan rekapitulasi,laporan penerimaan dan laporang pengeluaran kas.

\section{Daftar Pustaka}

[1] G. Abdullah, Kastaman, and S. G. Arnan, "Aplikasi Pengelolaan Kas Masuk dan Kas Keluar Berbasis Web pada Perusahaan xyz," J. Teknol. Inf., vol. 1, no. 4, pp. 131-138, 2012.

[2] K. Purwantini, D. Danang, and ..., "Sistem Informasi Akuntansi Penerimaan Dan Pengeluaran Kas Berbasis Multiuser Di Smk Pati Unus Karangawen Demak,”... Komputerisasi Akunt., vol. 13, no. 1, pp. 24-36, 2020, [Online]. Available: https://journal.stekom.ac.id/index.php/kompak/article/view/157.

[3] Rochim, A.N., Hasbi, M., Irawati, T., "Aplikasi Pengelolaan Keuangan Pada PT. Jala Prokreasi Surakarta.”. Jurnal Teknologi Informasi dan komunikasi STMIK Sinar Nusantara. 2012. https://p3m.sinus.ac.id/jurnal/index.php/TIKomSiN/article/download/129/22,

[4] Kadir, Sistem Pemrograman Database MySQL untuk Pemula. Jakarta: Medikom, 2013.

[5] Andi, Sistem Informasi Akuntansi: Esensi dan Aplikasi. Yogyakarta: CV. Andi Offset, 2017.

[6] Effendi, Prinsip-Prinsip Akuntansi Berbasis SAK ETAP. Jakarta: Rajawali Press, 2013.

[7] Mulyadi, Sistem Akuntansi. Jakarta: Salemba Empat, 2016. 